\title{
The Human Vaginal Microbiota: Boon or Bane
}

\section{PD Gupta}

Former, Director Grade Scientist, Centre for Cellular and Molecular Biology, Hyderabad, India.

Corresponding Author: PD Gupta, Former, Director Grade Scientist, Centre for Cellular and Molecular Biology, Hyderabad, India.

Received date: January 15, 2021; Accepted date: January 20, 2021; Published date: February 23,2021

Citation: P.D. Gupta (2021) The Human Vaginal Microbiota: Boon or Bane. J of Obstetrics Gynecology and Reproductive Sciences 5(1) DOI:10.31579/2578-8965/057

Copyright: (C) 2021, PD Gupta, This is an open access article distributed under the Creative Commons Attribution License, which permits unrestricted use, distribution, and reproduction in any medium, provided the original work is properly cited.

\begin{abstract}
We are soaked in microbiota, both, externally and internally. The balance between harmful and beneficial keeps us healthy, however even slight imbalance in their ratio may make cause of ill health. Many of the species of Lactobacillus keeps the vagina healthy; even some species of Lactobacillus are troublesome to the vagina. Other pathogenic bacteria and fungus cause many diseases. Lactobacillus spp prevents harmful bacteria to infect the vagina; nevertheless their population varies due to various factors mentioned in the text. Because of this the woman suffers even with infertility, abortions etc.
\end{abstract}

Keywords: vaginal microbiota; boon; bane

\section{Introduction}

The microbiota is the population of microscopic organisms that live in/on the human organs. The study of the microbiota became more serious in recent decades as researchers found that it played an important role in maintaining the health or diseased state of the host. Early on, it became apparent that some gut bacteria are beneficial and some are toxic, and figuring out which is which has been the subject of much recent study [1, $2]$. The healthy vagina has specific microbiota, too. Research on the microbiota is lagging behind compare to conducted on the microbiota of other parts of the body.

\section{Vaginal Microbiota}

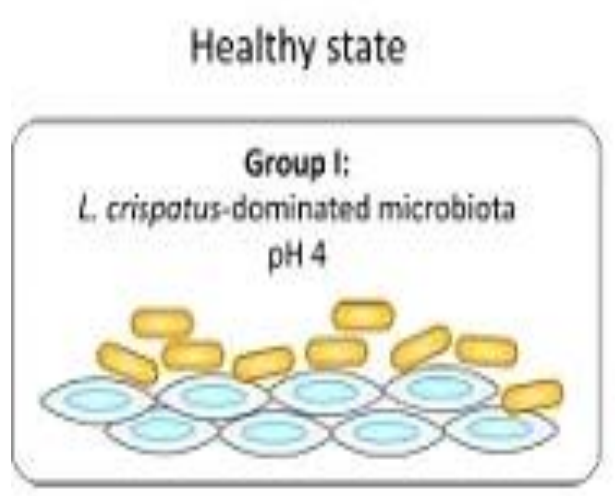

The vaginal microbiota are the microorganisms that colonize the human vagina. They were discovered by the German gynecologist Albert Döderlein in 1892. The amount and type of bacteria present have significant implications for a woman's overall health. More than a million bacterial genes that represent 300 different species along with the human vagina consists of some fungi and viruses. Together, these populations make up the vaginal microbiota.

In the vagina, microbes exist in a finely tuned mutualistic relationship with the host and provide the first line of defence against the colonization by opportunistic pathogens (Figure 1).

Figure 1. Vaginal Microbiota A. In healthy vagina and B diseased vagina

The species composition depends on many factors, however, both aerobic and anaerobic organism are found the pyrosequencing of barcoded 16S rRNA genes [3].

Factors affecting vaginal microbiota composition
Different factors could change the composition of vaginal microbiota, triggering modifications in this area. Some of these factors include the woman's age, pregnancy, ethnic race, presence of cancer, and smoking habit, among others. The composition of the vaginal microbiota changes throughout a woman's lifetime from birth, through puberty, reproductive 
age and menopause. The early childhood vaginal microbiota comprise a variety of anaerobes, diphtheroids.

coagulase-negative staphylococci, and E. coli, whereas postmenopausal women often experience a loss of Lactobacillus spp. associated with the decrease in estrogen controlling vaginal epithelial proliferation, maturation, and accumulation of glycogen, which is directly or indirectly nutritionally necessary for the maintenance of Lactobacillus spp.

Throughout a woman's lifespan, the vaginal microbiota undergoes major changes associated with transitional reproductive periods such as puberty and menopause, during these periods, the vaginal microbiota can affect host reproductive physiology but can also be affected by host physiology [4].

Some species associated with non-Lactobacillus vaginal microbiota may trigger immune responses as well as degrade the host mucosa, processes that ultimately increase susceptibility to infections and contribute to negative reproductive outcomes such as infertility and preterm birth. Further studies are needed to better understand the functional underpinnings of how the vaginal microbiota affect host physiology [5] but also how host physiology affects the vaginal microbiota. Understanding this fine-tuned interaction is a key to maintaining women's reproductive health.

\section{Normal v/s abnormal microbiota}

After its discovery the concept of normal versus abnormal microbiota in women began to emerge. The latter became known by the term "bacterial vaginosis" or BV. BV microbiota is dominated by Gardnerella vaginalis and includes a number of anaerobic organisms. BV microbiota is associated with vaginal discharge, poor pregnancy outcomes, pelvic inflammatory disease, post-operative wound infections, and endometritis following elective abortions. Additionally, BV microbiota predisposes women to infection by HIV as well as other STDs. [6].

These new findings will inform the design of future clinical investigations of the role of the vaginal microbiota in health and disease.

\section{Importance of Vaginal Microbiota}

A balance of bacteria: The primary colonising bacteria of a healthy vagina is called lactobacillus. It helps to keep the environment acidic and discourage other bacteria, yeast, and viruses from thriving. Not all types of lactobacilli are good, and there is at least one strain that puts women at a higher risk of acquiring a sexually transmitted infection. However, the women who lack a dominant lactobacillus in their microbiota are also at a higher risk of acquiring STIs and other conditions including bacterial vaginosis [7].

The role of the vaginal microbiome in fertility: The known pathogens such as Mycoplasma tuberculosis, Chlamydia trachomatis, and Neisseria gonorrhoeae can cause infertility, subclinical changes in the microbiota in states like bacterial vaginosis are also thought to be risk factors in subfertility [8]. In the article Hidden Reasons of Woman's Infertility: Microbiota Milieu, [9], we have described that certain microbiota milieu is responsible for Infertility.

Connection to disease and fertility: The vaginal microbiota plays an important role even to conceive a baby. There is also evidence to show that once a woman is pregnant, certain pathogens can cause a loss of pregnancy or adverse outcomes for the baby, Research into IVF has found the type of microorganisms present in the uterus at the time of embryo transfer interplay into the outcome of pregnancy [9].

Women with pelvic inflammatory disease - which usually occurs when sexually transmitted bacteria spread from the vagina to the uterus, fallopian tubes or ovaries - are more at risk of becoming infertile. [10].
"So [the microbiome] certainly interplays into developing infertility which might be tubal damage, but whether it interplays exactly into fertility outcome at the time is less understood, [8]"

Sexual activity and ethnicity influenced the composition of the vaginal microbiota of these young, relatively sexually inexperienced women. Women had consistent vaginal microbiota over time if lactobacilli were the dominant spp. present.

Penile-vaginal sex did not alter the consistency of microbial communities but increased G.vaginalis clade diversity in young women with and without BV, suggesting sexual transmission of commensal and potentially pathogenic natural group [11].

\section{Disruptions to the microbiome}

Modifiable and nonmodifiable factors are strongly associated with community composition, including behavior, race or ethnicity, and hygiene. Disruptions of normal vaginal flora have long been linked to pelvic inflammatory disease, 9 miscarriages, 10 and prematurity. There has been enormous recent growth in the understanding of the vaginal ecosystem, although the interactions among host, the external environment, and bacterial communities are very complex [12].

Sexual activity, lubricants, and semen can all change the composition of the microbiota, as well as hormonal contraceptives, menstruation and antibiotics. Antibiotics, just like in gut bacteria, can basically eliminate lactobacillus and give the opportunity to other bacteria that are not very welcome to grow and thrive [13]. Disruption of the microbiota can cause an imbalance of bacteria, which may lead to bacterial vaginosis. It can also trigger the overgrowth of the fungus, Candida. The ever-changing vaginal microbiota is also largely age-dependent; Dr Huston says [13].

Babies Need Healthy Microbiota. Just last month, researchers from the University of Cambridge added further fuel to the dispute when they scanned more than 500 placentas and found no evidence of bacterial DNA. They suggest that older studies were simply detecting experimental contaminants and the womb is, in fact, sterile. But the researchers may have just interpreted the data differently, says, a maternal-foetal medicine specialist at Baylor College of Medicine in Texas. She thinks they simply labelled some DNA sequences as contaminants rather than colonizers, leading them to conclude that no bacteria live in the placenta. Aagaard [14] was among the first to report bacterial DNA in the placenta.

\section{Mom's Inoculums}

The infant microbiota plays an essential role in human health and its assembly is determined by maternal-offspring exchanges of microbiota. This process is affected by several practices, including Cesarean section (C-section), perinatal antibiotics, and formula feeding that have been linked to increased risks of metabolic and immune diseases. The composition of the gut bacterial community is different in infants delivered by caesarean section from that of infants born by vaginal delivery [15]. Infants born by vaginal delivery are exposed to the mother's bacteria at birth, which influences the infant's gut bacteria and stimulates white blood cells and other components of the immune system [16]. Studies have suggested that infants born by caesarean section are at greater risk of developing obesity and/or diabetes than those born vaginally [15]. In a recent cross-sectional study of 8900 preschool children, the authors found that the odds of overweight were 1.35 and of obesity were 1.25 in children delivered by caesarean section [16]. A similar study in a small cohort also showed that the prevalence rates of overweight and obesity were $15.6 \%$ and $12.9 \%$, respectively, in 672 preschool children who were born by caesarean section [17]. Although more studies appear to support the association, many factors can influence the outcomes of these studies, including study population, sex of the offspring, and body weight of the mother. 
On the birth of individual, like a fingerprint, microbiota is also unique. Some of it may come from the mom, depending on how one is born. During vaginal delivery, babies get coated in their mother's microbiota as they go through the birth canal. But that doesn't happen in a C-section. Research shows that babies delivered by $\mathrm{C}$-section are more likely to grow up to have allergies, but it's not clear why.

Differences in bacterial populations between caesarean- and vaginally delivered babies, thought to account for the greater risk of health problems suffered by caesarean-born babies in later life, are most likely caused by antibiotics administered to mothers delivering by $\mathrm{C}$-section rather than lack of exposure to vaginal microbes at birth. [18]. 'Vaginal seeding,' whereby caesarean-delivered babies are immediately swabbed with the mother's vaginal fluids, is unjustified and potentially unsafe [19]. However, the long-term benefits of vaginal seeding are unclear. In addition, there's concern that vaginal infections, such as group B streptococcus, herpes, chlamydia and gonorrhea, could be passed from mother to baby. Further research is needed.

\section{Conclusion}

Like other body organs, Vagina is also loaded with microbiota. The vaginal microbiota keeps not only the host healthy, but her babies will also be born healthy provided she gives birth through her vaginal canal. C-section babies, who lacks on mother's inoculum suffers periodical infections generally until they develop their own immune system. Mother's seeding may not be very effective. Beneficial vaginal microbiota keeps the pathogenic bacteria at the bay, however due to other environmental conditions and life style factors, the pathogenic bacteria many chronic diseases, including infertility.

\section{Reference}

1. Sawicka, B., Kaid Johar, S. R., Sood, P. P. and Gupta, P. D. (2017) Imbalance of Gut Microbiota Induces Cancer: A Review J Cell Tissue Res 17(2) 6073-6084

2. Gupta, P. D (2018) Bacteria: The Powerful Creatures: A Mini Review J Cell Tissue Res. 18(3) 6555-6558

3. Jacques Ravel, Pawel Gajer, et al. (2011) Vaginal microbiome of reproductive- age women. PNAS ,108 (Supplement 1) 4680-4687

4. Farage $M \&$ Maibach $H$ (2005). Lifetime changes in the vulva and vagina. Arch Gynecol Obstet 273, 195-202.

5. Smith Steven B Ravel Jacques. (2017) The vaginal microbiota, host defence and reproductive physiology J Physiol. 595(2):451463.
6. Martin David H. (2012) The Microbiota of the Vagina and Its Influence on Women's Health and Disease Am J Med Sci. 343(1): 2-9.

7. Morris MC, Rogers PA, et al. (2001) Is bacterial vaginosis a sexually transmitted infection? Sexually Transmitted Infections; 77:63-68.

8. Van Oostrum N, De Sutter P, Meys J, Verstraelen H. (2013) Risks associated with bacterial vaginosis in infertility patients: a systematic review and meta- analysis. Hum Reprod. 28(7):18091815.

9. Gupta PD and Pushkala K. (2020) Hidden Reasons of Woman's Infertility: Microbiota Milieu Acta Scientific Women's Health 2 (2): $48-50$

10. https://www.womenshealth.gov/a-z-topics/pelvic-inflammatorydiseasehttps://www.womenshealth.gov/a-z-topics/pelvicinflammatory-disease

11. Lenka A Vodstrcil, Jimmy Twin et al. (2017) The influence of sexual activity on the vaginal microbiota and Gardnerella vaginalis clade diversity in young women PLoS One. 24;12(2):e0171856

12. Felicia M. T. Lewis, MD, Kyle T. Bernstein, and Sevgi O. Aral (2017) Vaginal Microbiome and Its Relationship to Behavior, Sexual Health, and Sexually Transmitted DiseasesObstet Gynecol. 129(4): 643-654.

13. Chee, W.J.Y., Chew, S.Y. \& Than, L.T.L (2020) Vaginal microbiota and the potential of Lactobacillus derivatives in maintaining vaginal health. Microb Cell Fact 19, 203

14. Aagaard Kjersti , Ma Jun et al. (2014) The placenta harbors a unique microbiome Sci Transl Med6(237):237ra65

15. Gupta PD (2020) It Matters, How Your Mother was born? Genomics \& Gene Therapy International Journal 4 ( 1) August 03, 2020

16. Gupta, P. D.1 and Tyagi, S (2020) Development of immune system from new born to adult: A new insight .2 J Cell Tissue Res 20(1) 6853-6860

17. H Li 1, R Ye, L Pei, A Ren, X Zheng, J Liu (2014) Caesarean delivery, caesarean delivery on maternal request and childhood overweight: a Chinese birth cohort study of 181380 children Pediatr Obes ;9(1):10-6.

18. Mueller Noel T., Bakacs Elizabeth et al. (2015) The infant microbiome development: mom matters Trends Mol Med.; 21(2): 109-117.

19. Vaginal seeding. (2017) Committee Opinion No. 725. American College of Obstetricians and Gynecologists. Obstet Gynecol.130:e274-8.

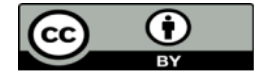

This work is licensed under Creative Commons Attribution 4.0 License

To Submit Your Article Click Here: Submit Article
Ready to submit your research? Choose Auctores and benefit from:

*ast, convenient online submission
rigorous peer review by experienced research in your field
*apid publication on acceptance
* authors retain copyrights
* inique DOI for all articles
immediate, unrestricted online access

At Auctores, research is always in progress.

Learn more www.auctoresonline.org/journals/obstetrics-gynecologyand-reproductive-sciences 